\title{
The Effect of Low-Level Laser on Postoperative Pain After Tibial Fracture Surgery: A Double-Blind Controlled Randomized Clinical Trial
}

\author{
Sholeh Nesioonpour ${ }^{1}$; Soheila Mokmeli ${ }^{2}$; Salman Vojdani ${ }^{1,{ }^{*}}$; Ahmadreza Mohtadi ${ }^{1}$; Reza \\ Akhondzadeh ${ }^{1}$; Kaveh Behaeen ${ }^{1}$; Shahnam Moosavi ${ }^{3}$; Sarah Hojjati ${ }^{4}$ \\ ${ }^{1}$ Department of Anesthesiology, Pain Research Center, Ahvaz Jundishapur University of Medical Sciences, Ahvaz, Iran \\ ${ }_{2}^{2}$ Canadian Optic and Laser Center, COL Center, Victoria, Canada \\ ${ }_{3}^{3}$ Department of Orthopedic, Ahvaz Jundishapur University of Medical Sciences, Ahvaz, Iran \\ ${ }^{4}$ Department of Physical Education and Sport Science, Bu-Ali Sina University, Hamedan, Iran \\ ${ }^{*}$ Corresponding author: Salman Vojdani, Department of Anesthesiology, Pain Research Center, Ahvaz Jundishapur University of Medical Sciences, Ahvaz, Iran. Tel: +98-6112220168, \\ Fax:+98-6112220168, E-mail:Vojdani.s@ajums.ac.i
}

Received: January 14, 2014; Revised: February 15, 2014; Accepted: February 24, 2014

\begin{abstract}
Background: Postoperative pain is a common complication that can lead to serious morbidities and delayed recovery.
Objectives: The aim of this study was to investigate the effect of low-level laser therapy on acute pain after tibial fracture surgery.

Patients and Methods: In this randomized clinical trial, 54 patients who were candidate for tibial fracture surgery were allocated randomly to two groups, namely, control and laser therapy. Both groups had the same type of surgery and technique of spinal anesthesia. Patients in laser group were treated with the combination of two lasers (GaALAs, $808 \mathrm{~nm}$; and GaALInP, $650 \mathrm{~nm}$ ) at the end of the surgery while control group received laser in turn-off mode with the same duration as laser group. Patients were evaluated for pain intensity according to the visual analogue scale (VAS) and the amount of analgesic use during 24 hours after surgery.

Results: Laser group experienced less pain intensity in comparison with control group at second, fourth, eighth, $12^{\text {th }}$, and $24^{\text {th }}$ hours after surgery (P Value $<0.05$ ). In addition, the amount of consumed opioid in laser group was significantly less than the control group (51.62 \pm 29.52 and $89.28 \pm 35.54 \mathrm{mg}$, respectively; P Value, 0.008).

Conclusions: Low Level Laser Therapy is a proper method to reduce postoperative pain because it is painless, safe and noninvasive and is easily accepted by patients.
\end{abstract}

Keywords: Low Level Laser Therapy; Postoperative Pain; Tibial Fracture Surgery

\section{Background}

One of the undesirable complications of surgery is postoperative pain that may result in serious morbidities such as agitation, hypertension, mood changing, tachycardia $(1,2)$ and delay in wound healing, which can be more dangerous in patients with the underlying diabetes mellitus, hypertension, or coronary heart diseases as it may lead to fatal complications such as myocardial infarction (3). There is a high variability among patients in tolerance to pain and analgesic requirement $(4,5)$. The studies show that about $80 \%$ of patients experience a mild to severe pain after surgery (6). There is inadequate postoperative analgesia in the half of all surgeries, can lead to chronic postoperative pain (7). Several methods are available to control and reduce postoperative pain such as administering opioids or nonsteroidal anti-inflammatory drugs (NSAIDs) and patient-controlled analgesia (PCA). It is established that the use of systemic opioids alone is not sufficient to relieve postoperative pain. In most cases, inadequate dosage is prescribed to reduce the side effects of these drugs like respiratory depression and therefore, the medication cannot control pain completely $(8,9)$. Analgesic nephropathy, skin reactions, and peptic ulcers are common side effects of nonsteroidal anti-inflammatory drugs (10). Recent advances present new techniques for prevention and reduction of postoperative pain. One of the most important technologies of this century is the use of low-level laser (LLL) at the site of surgery (11).

Low-level laser therapy (LLLT) was pioneered at Russia and Hungry and then at Europe in early 1960s. It is a branch of laser treatments that has been indicated for pain killing and wound healing. LLLT uses irradiation with laser light of low intensity and its effects are not due to producing heat. These nonthermal effects are thought to be mediated by a photochemical reaction that alters cell membrane permeability, leading to increased mRNA synthesis and cell proliferation. FDA has started differ- 
ent investigations on LLLT for 15 years and has approved the use of LLLT for pain relief in carpal tunnel syndrome since $2002(11,12)$. It is also used to treat damages in sport injuries and musculoskeletal disorders. In addition, it is applicable to reduce neck pain and the size of keloid scarring after surgery (13-17). Many studies found that LLL stimulates respiratory cycle in mitochondria and increases adenosine triphosphate molecules (14) that reduce swelling and pain (16). In another study, applying LLL directly over painful points was useful in treatment of stress fracture of tibia (18). The LLL is effective in relieving pain of knee osteoarthritis, breast augmentation surgery, and cryosurgical treatment of oral leukoplakia $(15,17)$.

\section{Objectives}

Pain following orthopedic surgeries are considered severe pain $(19,20)$; hence, the aim of this study was to investigate the effect of LLLT on acute pain after tibial fracture surgery.

\section{Patients and Methods}

This double-blind, controlled, randomized clinical trial was conducted in 2012-2013 in Imam Khomeini Hospital, Ahvaz, Iran. The study was approved by the Ethical Committee of Jundishapur University of Medical Sciences (ETH-654) and all subjects signed an informed consent.

Sample size was calculated at 27 in each arm of the study by setting the power at $80 \%$ and the values for $Z_{1}$ ${ }_{\alpha \mid 2}, \mathrm{Z}_{1-\beta}, \mathrm{P}_{1}$, and $\mathrm{P}_{2}$ at $1.96,0.84,0.68$, and 0.32 , respectively, based on a previous observational study (21). A total of 54 patients aged between 18 and 60 years who were candidate for tibial fracture surgery in American Society of Anesthesiologists (ASA) classes I and II were allocated randomly to two equal groups of control and laser. All subjects were matched based on their age, weight, and height. Patients who were pregnant, those with malignant tumors, benign tumors with malignant potential, hypersensitivity to light, e.g. systemic lupus erythematosus, coagulopathies, high intracranial pressure, history of chronic pain, those on long-term opioids or other painkillers during the preceding month, or those who did not agree to undergo spinal anesthesia were excluded from the study.

Monitoring equipment including electrocardiograph, pulse oximeter and sphygmomanometer were employed for all patients; they received $10-\mathrm{mL} / \mathrm{kg}$ intravenous lactated Ringers' solution and then spinal anesthesia was induced by the anesthesiologist.

Spinal anesthesia was induced by intrathecal administration of 10-mg 0.5\% bupivacaine (Astrazeneca Co., Germany) with 25-gauge needle in the sitting position and with the midline technique.

If the systolic blood pressure dropped by $20 \%$ or more, 10-mg ephedrine would be injected intravenously. Upon achieving successful anesthesia, pull-tight elasticated tourniquet was clamped and operation was started. The surgical procedures were similar in both groups and included open reamed interlocking intramedullary nailing, which is the preferred approach for treatment of tibial shaft fractures (22).

After the surgery and before the final bandage in surgery room, patients in laser group were treated with a combination of two lasers (Canadian Optic and Laser Center, Canada): (1) GaALAs hand held probe (PLP-IR) with wavelength of $808 \mathrm{~nm}$ and 300-mW output power in continuous mode (dose, $6 \mathrm{~J} / \mathrm{cm}^{2}$; area, $1 \mathrm{~cm}^{2}$; and time, 20 s/point); and (2) GaALInP hand held probe (PLP-R) with wavelength of $650 \mathrm{~nm}$ and 100-mW output power in continuous mode, (dose, $3 \mathrm{~J} / \mathrm{cm}^{2}$; area, $1 \mathrm{~cm}^{2}$; and time, $30 \mathrm{~s}$ /point).

Each tibial fracture was radiated from four sides in contact technique with the combination of IR and $\mathrm{R}$ laser in dose of $9 \mathrm{~J} / \mathrm{cm}^{2}$ (medial, lateral, anterior, and posterior sides of fracture region and popliteal fossa). For radiation on popliteal fossa, the legs were elevated by $60^{\circ}$ angels.

In addition, trigger points on muscles and surgical wounds (6-8 points) were radiated with $4 \mathrm{~J} / \mathrm{cm}^{2}$ by the same combination of IR and R lasers (ten seconds of each laser; $3 \mathrm{~J} /$ point IR plus $1 \mathrm{~J} /$ point R laser).

For placebo laser treatment in control group, all those sites were treated with the lasers in turn-off mode with the same duration.

One of authors who was blind to the group allocation and did not participate in the laser therapy procedures, filled out the questionnaires. The amount of total analgesic and pain intensity at second, fourth, eighth, $12^{\text {th }}$, and $24^{\text {th }}$ hours after the surgery were investigated in both groups. Pain intensity was quantified by visual analogue scale (VAS) in which zero and ten represented analgesia and worst possible perception of pain, respectively. If VAS was three or more, $0.3 \mathrm{mg} / \mathrm{kg}$ of pethidine was injected intravenously.

\subsection{Statistical Analysis}

The data are presented as mean \pm standard deviation (SD). We performed Shapiro-Wilk test and Levene's test for normality of the data distribution and equality of variances. Independent samples $t$ test, repeated measure test, and Bonferroni post hoc test were used to analyze the data. P Value of less than 0.05 was considered as statistically significant. All the statistical analyses were done by SPSS software version 16 (SPSS Inc, Chicago, IL, USA).

\section{Results}

Demographic characteristics of participants are presented in Table 1. Two groups were similar in terms of age, weight, height, and body mass index. There was no significant difference between groups regarding the duration of surgery (57.34 \pm 3.2 and $56.29 \pm 3.4$ minutes in control and laser groups, respectively; $\mathrm{P}=0.71$ ) and anesthesia duration ( $84.14 \pm 5.21$ and $85.02 \pm 4.98$ minutes in control and laser groups, respectively; $\mathrm{P}=0.69$ ). 
Nesioonpour S et al.

\begin{tabular}{lcccc}
\hline \multicolumn{5}{l}{ Table 1. Demographic Characteristics of the Participants $\mathrm{a}, \mathrm{b}$} \\
\hline Groups & Age, $\mathbf{y}$ & Weight, kg & Height, cm & BMI, kg/m ${ }^{2}$ \\
\hline $\begin{array}{l}\text { Control } \\
\text { Group }\end{array}$ & $24.61 \pm 2.76$ & $71.22 \pm 11.34$ & $169 \pm 6$ & $72.16 \pm 12.71$ \\
$\begin{array}{l}\text { LLLT } \\
\text { Group }\end{array}$ & $25.05 \pm 2.68$ & $72.27 \pm 10.80$ & $171 \pm 5$ & $70.09 \pm 13.23$ \\
P value & 0.628 & 0.777 & 0.791 & 0.706 \\
\hline
\end{tabular}

a Abbreviations: LLLT, low-level laser therapy; and BMI, body mass index. $\mathrm{b}$ Data are presented as mean \pm SD.

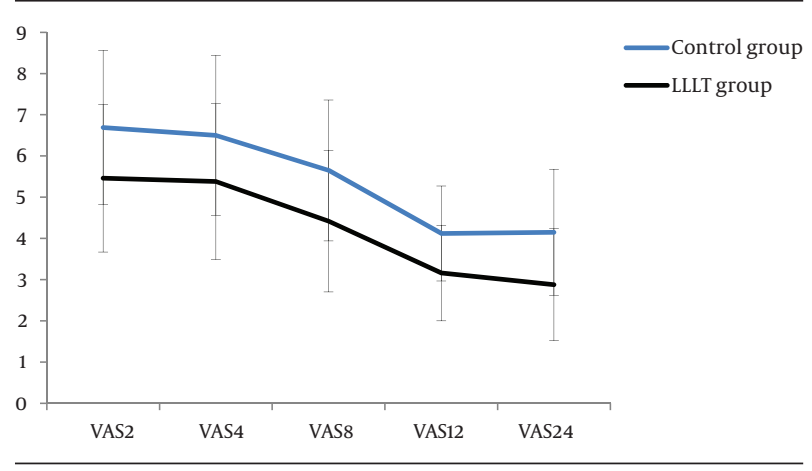

Figure 1. Pain Intensity at Different Hours in lllt and Control Groups

\begin{tabular}{|c|c|c|c|c|c|}
\hline \multirow[t]{2}{*}{ Groups } & \multicolumn{5}{|c|}{ VAS at Different Time Points After Surgery } \\
\hline & $2^{\text {nd }} \mathbf{h}$ & $4^{\text {th }} \mathbf{h}$ & $\mathbf{8}^{\text {th }} \mathbf{h}$ & $12^{\text {th }} \mathbf{h}$ & $24^{\text {th }} \mathbf{h}$ \\
\hline $\begin{array}{l}\text { Control } \\
\text { Group }\end{array}$ & $6.69 \pm 1.87$ & $6.50 \pm 1.94$ & $5.65 \pm 1.71$ & $4.12 \pm 1.15$ & $4.15 \pm 1.53$ \\
\hline $\begin{array}{l}\text { LLLT } \\
\text { Group }\end{array}$ & $5.46 \pm 1.79$ & $5.38 \pm 1.89$ & $4.42 \pm 1.72$ & $3.16 \pm 1.16$ & $2.88 \pm 1.36$ \\
\hline P value & 0.019 & 0.041 & 0.013 & 0.006 & 0.012 \\
\hline
\end{tabular}

a Abbreviations: LLLT, low-level laser therapy; and VAS, visual analogue scale. $\mathrm{b}$ Data are presented as mean \pm SD.

Based on VAS, mean scores of pain intensity after operation in different periods are presented in Table 2. Pain reduced considerably at second, fourth, eighth, $12^{\text {th }}$, and $24^{\text {th }}$ hours after surgery in laser group in comparison with the control group. Although there were no significant differences in pain intensity between the second and fourth, the fourth and eighth, the eighth and $12^{\text {th }}$, as well as the $12^{\text {th }}$ and $24^{\text {th }}$ hours in each group $(\mathrm{P}>0.999$, $\mathrm{P}=0.110, \mathrm{P}=0.681$, and $\mathrm{P}>0.999$ in control group; $\mathrm{P}>$ 0.999, $\mathrm{P}=0.099, \mathrm{P}=0.097$, and $\mathrm{P}>0.999$ in laser group, respectively), there were significant differences between the second and eighth, the second and $12^{\text {th }}$, the second and $24^{\text {th }}$, the fourth and $12^{\text {th }}$, the fourth and $24^{\text {th }}$, as well as the eighth and $24^{\text {th }}$ in each group $(\mathrm{P}<0.001, \mathrm{P}=0.010$, $\mathrm{P}<0.001, \mathrm{P}=0.009, \mathrm{P}<0.001$, and $\mathrm{P}=0.002$ in control group; $\mathrm{P}<0.001, \mathrm{P}=0.002, \mathrm{P}<0.001, \mathrm{P}=0.002, \mathrm{P}<0.001$, and $\mathrm{P}<0.001$ in lase group, respectively; Figure 1 ).

The mean of total amount of analgesic (pethidine) used in laser group was significantly less than control group.
The mean of total amount of analgesic was $51.62 \pm 29.52$ and $89.28 \pm 35.54 \mathrm{mg}$ in laser and control groups, respectively $(\mathrm{P}=0.008)$.

\section{Discussion}

Pain as a stressor, stimulates the physiological and psychological responses. Its outcomes have a direct effect on the postoperative complications, recovery time, and patient's satisfaction with the health system. The aim of this study was to investigate the effect of LLL with the wavelengths 650 and $808 \mathrm{~nm}$ on pain after tibial fracture surgery. The results of this study showed that pain reduction was significant at the second, fourth, eighth, $12^{\text {th }}$, and $24^{\text {th }}$ hours after surgery (P Value $\leq 0.05$ ). Similarly, Moore et al. showed that low level gallium-aluminum-arsenide laser for four to six minutes at the end of the cholecystectomy had no significant effect on pain reduction at the first and the fourth hours after surgery; however, the effect was significant at the eighth, $12^{\text {th }}, 24^{\text {th }}$, and $48^{\text {th }}$ hours after surgery (21). Hegedus et al. reported that the use of LLL (wavelength, $830 \mathrm{~nm}$; continuous wave; and power, $50 \mathrm{~mW}$ ) in patients with knee osteoarthritis resulted in pain reduction and improvement in joint movement (15). Jackson et al. found that laser irradiation with wavelength of 630 to $640 \mathrm{~nm}$ at the beginning and at the end of breast augmentation surgery reduced the postoperative pain (23). Moreover, Ribeiro et al. reported that AsGaAl laser $(660 \mathrm{~nm})$ could decrease the pain as well as postoperative recurrence rate in patients with oral leukoplakia (17).

The results of our study showed the mean total amount of analgesic use in laser group was significantly lower than the control group $(\mathrm{P}<0.05)$. This finding is consistent with the findings of other researchers who reported that LLLT could decrease pain during and after the surgery and had a positive effect on wound healing and edema (12). LLLT is used in muscular fatigue (24), wound healing, and pain reduction in dental procedures in patients with and without diabetes (25-27). The researches showed that LLL could cause analgesia by reducing prostaglandin E2 $(28,29)$, raising endorphin level, and increasing urinary excretion of serotonin, the pain receptors stimuli. LLLT also has a negative effect on pain neurotransmitters and prevents accumulation of acetylcholine, a pain stimulus in the receptors (30).

The results of this study showed that the combination of laser therapy and analgesic medications had better effect during the 24 hours of recovery after the surgery. Laser radiation at wavelengths of 650 and $808 \mathrm{~nm}$ ( $R$ and IR laser) can decrease postoperative pain and analgesic use in postoperative period. LLLT does not have side effects like respiratory depression, skin reaction, and analgesic nephropathy that are seen with other methods. It is recommended to perform more studies concerning the applications of LLLT in anesthesia field as it is a noninvasive, safe, and acceptable analgesic method in patients in recovery or surgery room. 


\section{Acknowledgements}

The paper was issued from thesis of Dr Salman Vojdani. Hereby, we acknowledge the vice chancellor of Deputy of Research and Technology Affairs of Ahvaz Jundishapur University of Medical Sciences, especially Research Consultation Center (RCC) for technical support. We wish to thank Bahareh Beshavardi Nejad for her collaboration.

\section{Authors' Contributions}

Study concept and design: Sholeh Nesioonpour and Soheila Mokmeli. Analysis and interpretation of data: Sarah Hojjati and Salman Vojdani. Manuscript preparation: Salman Vojdani, Ahmadreza Mohtadi, Reza Akhondzadeh, Kaveh Behaeen, and Shahnam Moosavi. Collection of data: Salman Vojdani and Sarah Hojjati. Critical revision: Sholeh Nesioonpour.

\section{Funding/Support}

The financial support (Grant No. U-91189) was provided by Ahvaz Jundishapur University of Medical Sciences, vice chancellor for research and technology.

\section{References}

1. Imani F, Rahimzadeh P, Faiz SH. Comparison the efficacy of adding clonidine, chloropromazine, promethazine and midazolam to morphine pumps in postoperative pain control of addicted patients. Anesth Pain Med. 2011;1(1):10-4.

2. Shoar S, Esmaeili S, Safari S. Pain Management After Surgery: A Brief Review . Anesth Pain Med. 2012;1(3):184-6.

3. Ledowski T, Reimer M, Chavez V, Kapoor V, Wenk M. Effects of acute postoperative pain on catecholamine plasma levels, hemodynamic parameters, and cardiac autonomic control. Pain. 2012;153(4):759-64.

4. Nesioonpour S, Akhondzadeh R, Pipelzadeh MR, Rezaee S, Nazaree $\mathrm{E}$, Soleymani $\mathrm{M}$. The effect of preemptive analgesia with bupivacaine on postoperative pain of inguinal hernia repair under spinal anesthesia: a randomized clinical trial. Hernia. 2013;17(4):465-70.

5. Hosseini Jahromi SA, Sadeghi poor S, Hosseini Valami SM, Javadi A. Effects of Suppository Acetaminophen, Bupivacaine Wound Infiltration, and Caudal Block With Bupivacaine on Postoperative Pain in Pediatric Inguinal Herniorrhaphy. Anesth Pain Med. 2012;1(4):243-7.

6. Apfelbaum JL, Chen C, Mehta SS, Gan TJ. Postoperative pain experience: results from a national survey suggest postoperative pain continues to be undermanaged. Anesth Analg. 2003;97(2):534-40.

7. Imani F, Rahimzadeh P. Gabapentinoids: gabapentin and pregabalin for postoperative pain management. Anesth Pain Med 2012;2(2):52-3.

8. Nayman J. Measurement and control of postoperative pain. Ann R Coll Surg Engl. 1979;61(6):419-26.

9. Sieber FE, Mears S, Lee H, Gottschalk A. Postoperative opioid consumption and its relationship to cognitive function in older adults with hip fracture. J Am Geriatr Soc. 2011;59(12):2256-62.

10. Altunkaya H, Ozer Y, Kargi E, Ozkocak I, Hosnuter M, Demirel CB, et al. The postoperative analgesic effect of tramadol when used as subcutaneous local anesthetic. Anesth Analg. 2004;99(5):1461-4.

11. Asnaashari M, Safavi N. Application of Low level Lasers in Dentistry (Endodontic). J Lasers Med Sci. 2013;4(2):57-66.
12. Prabhu V, Rao SB, Chandra S, Kumar P, Rao L, Guddattu V, et al Spectroscopic and histological evaluation of wound healing progression following Low Level Laser Therapy(LLLT).J Biophotonics. 2012;5(2):168-84

13. Bjordal JM, Johnson MI, Iversen V, Aimbire F, Lopes-Martins RA Low-level laser therapy in acute pain: a systematic review of possible mechanisms of action and clinical effects in randomized placebo-controlled trials. Photomed Laser Surg. 2006;24(2):158-68.

14. Hopkins JT, McLoda TA, Seegmiller JG, David Baxter G. LowLevel Laser Therapy Facilitates Superficial Wound Healing in Humans: A Triple-Blind, Sham-Controlled Study. J Athl Train. 2004;39(3):223-9.

15. Hegedus B, Viharos L, Gervain M, Galfi M. The effect of low-level laser in knee osteoarthritis: a double-blind, randomized, placebo-controlled trial. Photomed Laser Surg. 2009;27(4):577-84.

16. Carvalho RL, Alcantara PS, Kamamoto F, Cressoni MD, Casarotto RA. Effects of low-level laser therapy on pain and scar formation after inguinal herniation surgery: a randomized controlled single-blind study. Photomed Laser Surg. 2010;28(3):417-22.

17. Ribeiro AS, Salles PR, da Silva TA, Mesquita RA. A review of the nonsurgical treatment of oral leukoplakia. Int $J$ Dent. 2010;2010:186018.

18. Chauhan A, Sarin P. Low level laser therapy in treatment of stress fractures tibia: A prospective randomized trial. Med J Armed Force Ind. 2006;62(1):27-9.

19. Rubio Pascual P, de la Cruz Bertolo J. [Pediatric acute postoperative pain management service: 6 years' experience]. Rev Esp Anestesiol Reanim. 2006;53(6):346-53.

20. Gramke HF, de Rijke JM, van Kleef M, Raps F, Kessels AG, Peters ML, et al. The prevalence of postoperative pain in a cross-sectional group of patients after day-case surgery in a university hospital. Clin J Pain. 2007;23(6):543-8.

21. Moore KC, Hira N, Cruikshank JA. The Effect of Infra-Red Diode Laser Irradiation on the Duration and Severity of Postoperative Pain: A Double Blind Trial. Laser T.1992;4(4):145-9.

22. Brumback RJ, Ellison TS, Poka A, Bathon GH, Burgess AR. Intramedullary nailing of femoral shaft fractures. Part III: Longterm effects of static interlocking fixation. J Bone Joint Surg Am. 1992;74(1):106-12.

23. Jackson R, Roche G, Mangione T. Low-level laser therapy effectiveness for reducing pain after breast augmentation. Am J Cosmet Surg. 2009;26(3):144-8.

24. de Almeida P, Lopes-Martins RA, De Marchi T, Tomazoni SS, Albertini R, Correa JC, et al. Red (660 nm) and infrared (830 nm) lowlevel laser therapy in skeletal muscle fatigue in humans: what is better? Lasers Med Sci. 2012;27(2):453-8.

25. Doshi-Mehta G, Bhad-Patil WA. Efficacy of low-intensity laser therapy in reducing treatment time and orthodontic pain: A clinical investigation. Am J Orthod Dentofac . 2012;141(3):289-97.

26. Obradovic R, Kesic L, Mihailovic D, Antic S, Jovanovic G, Petrovic A, et al. A histological evaluation of a low-level laser therapy as an adjunct to periodontal therapy in patients with diabetes mellitus. Lasers Med Sci. 2013;28(1):19-24.

27. Artes-Ribas M, Arnabat-Dominguez J, Puigdollers A. Analgesic ef fect of a low-level laser therapy $(830 \mathrm{~nm})$ in early orthodontic treatment. Lasers Med Sci. 2013;28(1):335-41.

28. Kreisler MB, Haj HA, Noroozi N, Willershausen B. Efficacy of low level laser therapy in reducing postoperative pain after endodontic surgery-- a randomized double blind clinical study. Int J Oral Maxillofac Surg. 2004;33(1):38-41.

29. Bjordal JM, Lopes-Martins RA, Joensen J, Couppe C, Ljunggren AE Stergioulas A, et al. A systematic review with procedural assessments and meta-analysis of low level laser therapy in lateral elbow tendinopathy (tennis elbow). BMC Musculoskelet Disord. 2008;9:75.

30. Mokmeli S, Khazemikho N, Niromanesh S, Vatankhah Z. The application of low-level laser therapy after cesarean section does not compromise blood prolactin levels and lactation status. Photomed Laser Surg. 2009;27(3):509-12. 